\title{
Longitudinal vibrations of viscoelastic longitudinally nonuniform rod under power load distributed along its length
}

\author{
Gera B. ${ }^{1}$, Sitarz M. ${ }^{2}$, Bolzhelarskyi Ya. ${ }^{1}$ \\ ${ }^{1}$ Dnipropetrovsk National University of Railway Transport named after Academician V. Lazaryan \\ 12a Ivanny Blazhkevych str., 79052, Lviv, Ukraine \\ ${ }^{2}$ The University of Dambrowa Górnicza \\ 1c Cieplaka str., 41-300, Dambrowa Górnicza, Poland
}

(Received 1 December 2016)

\begin{abstract}
In this article, the dynamic behavior of a moving elongated object is simulated using the relations for a viscoelastic rod, which moves at a constant speed under the action of traction force and distributed along its length external forces of resistance. We investigate the change of displacements and internal forces after the sudden application in the rod section of the local force directed longitudinally. The correlations of the initial boundary value problem that describes the dynamic behavior of the rod are written down, and its solution is obtained in the form of a series expansion in terms of eigenfunctions. For a viscoelastic rod consisting of three connected uniform rods, the analysis of wave processes induced by the application to the rod of a sudden concentrated force that resists the motion is carried out. This affects the motion of the rod as a whole, and induces the wave processes, the propagation and reflection of waves on the inner surfaces of joints. The comparison is performed for the behavior of an elastic, piecewise nonuniform rod and a viscoelastic rod with different mechanical characteristics, where the waves during their propagation are damped and smoothed.
\end{abstract}

Keywords: viscoelastic rod, propagation and reflection of longitudinal wave, resistance to motion.

2000 MSC: $74 \mathrm{H} 10$

UDC: 539.3

\section{Introduction}

The study of longitudinal vibrations of elastic and viscoelastic rods subjected to an intensive external loading was dealt with in a number of papers. Without going into a full review, let us indicate the directions of studies of the longitudinal dynamics of a rod. The theory of elastic waves in rods and bars is covered in [1]. The collision of uniform elastic rod with an obstacle and further propagation of elastic waves in it are described in [2]. The arrival of longitudinal elastic waves in a rod as a result of an impact on one of its ends is shown in [3] and the wave process in a rod with a slow change in its cross-section is being studied in [4]. The approach proposed in this work can be extended to the case of viscoelastic rod. Problems, which can be reduced to the solving the equation of nonuniform rod vibrations, including the variable cross-section and with variable elastic characteristics are considered in [5-7]. Analytical solutions of the equations to determine the longitudinal vibrations of nonuniform elastic rod are obtained in $[8,9]$ and the problem on determination of the optimal regime of longitudinal loading of one-dimensional moving mechanic system that provides the absence of undesired elastic vibrations caused by traction or braking forces is shown in [10]. The review of theoretical and experimental works on the investigation and propagation of nonlinear viscoelastic waves in the case of one-dimensional deformation, as well as the shock waves and accelerated waves are given in [10]. The longitudinal vibrations of viscoelastic rod with different forms of vibrations depending on its form are considered in [11], in which also there is given a complete enough overview of articles of this area of research. 
Studying the dynamics of moving rod is important for safe vehicles operation. For this purpose, there are determined the longitudinal elastic vibrations of rods, which simulate the motion of a train, including the rods with nonuniform characteristics [12-14]. The model of viscoelastic rod is more physically corresponding to the train motion because it consists of both elastic elements and elements, which are vibration absorbers.

The studies, which used the solutions of the problems for the rod motion, show that the sudden application of power load to an elastic rod in the direction of its axis, must give rise to the longitudinal dynamic deformations and stresses that exceed the elastic limit. It should be taken into account that the increase in the initial velocity of the rod motion in a medium that resists the movement leads to an increase in the resistances distributed throughout its length, to an elongation, and to the arising of internal tensile forces.

In this paper, a longitudinally nonuniform, composed of heterogeneous elements viscoelastic rod is considered, which moves due to the force applied to one of its ends and undergoes the forces from the external medium resistant to its motion. Provided establishing the constant velocity, the elastic dynamic effects in the rod do not arise and only an emergence of additional intensive load directed oppositely to the motion leads to longitudinal dynamic deformations and stresses. Various cases of changes of external forces based on their laws have been analysed by example of a moving train.

The objective of this work is to construct a mathematical model that allows studying the dynamic effects caused by the intensive transient regimes of the longitudinal force load of moving viscoelastic rod, to obtain a solution of the problem based on the data that must indicate the emergence of such obstacles to a motion of such systems as a rail train, to analyse the development of dynamic process based on the values of characteristics related to the viscosity influence.

\section{Problem formulation}

Let us consider a thin viscoelastic longitudinally nonuniform rod of the given length $L$. Direct the $x$-axis along the rod so that the rod domain is determined by the condition $x \in(0 ; L)$. At the end $x=L$, to the rod there is applied the variable in time $t$ force $F_{0}(t)$, and the end $x=0$ is free of load.

Along the rod, there act the distributed forces $\varpi(x, t)$ directed in the opposite to the force $F_{0}(t)$ direction so that the forces applied to the rod are balanced, $F_{0}(t)=\int_{0}^{L} \varpi(x, t) d x$ and under the action of forces $F_{0}(t)$ and $\varpi(x, t)$, the rod is in a state of strain.

At the instant $t=0$ at the point $x=x_{*}$, to the strained rod a concentrated force $P_{*}(t)$ is suddenly applied. This leads to arriving of a longitudinal wave and to a change of the displacement of the rod as a whole.

The equation to determine the displacements of the points of the nonuniform rod, following [12] and using the generalized function $\delta(x)$ to set a point of application of concentrated force $P_{*}(t)$, is written as follows

$$
\rho(x) \frac{\partial^{2} u(x, t)}{\partial t^{2}}-\frac{\partial}{\partial x}\left(k(x)\left(\frac{\partial u(x, t)}{\partial x}+\mu_{u} \frac{\partial^{2} u(x, t)}{\partial x \partial t}\right)\right)=-\varpi(x, t)-\delta\left(x-x_{*}\right) P_{*}(t),
$$

where is a coordinate along the axis, $t$ is time, $u(x, t)$ is a displacement of the rod particles, $\rho(x)=$ $\rho_{V}(x) S(x)$ is the rod density reduced to the axis, where $\rho_{V}(x)$ is the density function, $S(x)$ is the cross-sectional area of the rod, $k(x)=E(x) S(x)$ is a reduced modulus of elasticity, $E(x)$ is a modulus of elasticity, $\mu_{u}$ is a coefficient of material inelastic resistance for longitudinal vibrations. Note that $\mu_{u}$ also can depend on the coordinates, but such detail is not regarded in this investigation.

Eq. (1) is considered with the boundary conditions corresponding to the absence of external force at the end $x=0$ and to the imposing the force $F_{0}(t)$ at the border $x=L$, namely

$$
\left.\left(\frac{\partial u(x, t)}{\partial x}+\mu_{u} \frac{\partial^{2} u(x, t)}{\partial x \partial t}\right)\right|_{x=0}=0, \text { and }\left.k(x)\left(\frac{\partial u(x, t)}{\partial x}+\mu_{u} \frac{\partial^{2} u(x, t)}{\partial x \partial t}\right)\right|_{x=L}=F_{0}(t), \quad t>0 .
$$

Mathematical Modeling and Computing, Vol.3, No. 2, pp. 135-145 (2016) 
The initial conditions for the motion and the relative velocity are the following

$$
\left.u(x, t)\right|_{t=0}=f_{0}(x),\left.\quad \frac{\partial u(x, t)}{\partial t}\right|_{t=0}=f_{1}(x), \quad x \in(0 ; L) .
$$

The function $f_{0}(x)$ sets the initial displacement of the rod and $f_{1}(x)$ is the velocity distribution at the initial time.

In order to convert the conditions (2) into uniform ones, the force $F_{0}(t)$ is included into the motion equation and written as follows

$$
\begin{gathered}
\rho(x) \frac{\partial^{2} u(x, t)}{\partial t^{2}}-\frac{\partial}{\partial x}\left(k(x)\left(\frac{\partial u(x, t)}{\partial x}+\mu_{u} \frac{\partial^{2} u(x, t)}{\partial x \partial t}\right)\right)=\delta(x-L) F_{0}(t)-\varpi(x, t)-\delta\left(x-x_{*}\right) P_{*}(t), \\
x \in(0 ; L), t>0 .
\end{gathered}
$$

Then Eq. (4) is considered with the uniform boundary conditions

$$
\left.\left(\frac{\partial u(x, t)}{\partial x}+\mu_{u} \frac{\partial^{2} u(x, t)}{\partial x \partial t}\right)\right|_{x=0}=0,\left.\quad\left(\frac{\partial u(x, t)}{\partial x}+\mu_{u} \frac{\partial^{2} u(x, t)}{\partial x \partial t}\right)\right|_{x=L}=0, \quad t>0
$$

and with the initial conditions (3).

From the solution of the initial boundary value problem (4), (5), and (3) we determine the rod particles displacement. With this, the change of the longitudinal force in the rod can be expressed in terms of displacement as follows

$$
\Phi(x, t)=k(x)\left(\frac{\partial u(x, t)}{\partial x}+\mu_{u} \frac{\partial^{2} u(x, t)}{\partial x \partial t}\right) .
$$

Note that the motion of the rod as a whole due to, in particular, the initial conditions (3) does not affect the longitudinal force obtained by the formula (6). The internal longitudinal forces depend only on the rod deformation caused by the external forces.

\section{Problem solution representation}

Since the problem (4), (5), and (3) is linear, we can decompose its solution and present it as a sum of solution of the homogeneous equation corresponding to (4) with the inhomogeneous initial conditions (3) and the heterogeneous equation (4) with homogeneous initial conditions.

To find a solution of the homogeneous equation

$$
\rho(x) \frac{\partial^{2} u(x, t)}{\partial t^{2}}-\frac{\partial}{\partial x}\left(k(x)\left(\frac{\partial u(x, t)}{\partial x}+\mu_{u} \frac{\partial^{2} u(x, t)}{\partial x \partial t}\right)\right)=0,
$$

we apply the method of separation of variables. Represent $u(x, t)=X(x) \Theta(t)$ and substitute it into Eq. (7).

$$
\rho(x) X(x) \ddot{\Theta}(t)-\frac{d}{d x}\left(k(x) X^{\prime}(x)\left(\Theta(t)+\mu_{u} \dot{\Theta}(t)\right)\right)=0 .
$$

Hence we obtain

$$
\frac{\ddot{\Theta}(t)}{\Theta(t)+\mu_{u} \dot{\Theta}(t)}=\frac{1}{\rho(x) X(x)} \frac{d}{d x}\left(k(x) \frac{d X(x)}{d x}\right)=-\lambda^{2},
$$

or an equation to determine $X(x)$

$$
\frac{d}{d x}\left(k(x) \frac{d X(x)}{d x}\right)=-\lambda^{2} \rho(x) X(x)
$$


and the function $\Theta(t)$

$$
\frac{d^{2} \Theta(t)}{d t^{2}}+\lambda^{2} \mu_{u} \frac{d \Theta(t)}{d t}+\lambda^{2} \Theta(t)=0
$$

After substitution $u(x, t)=X(x) \Theta(t)$ into the boundary conditions (5) we obtain

$$
\frac{d X(x)}{d x} \Theta(t)+\mu_{u} \frac{d X(x)}{d x} \frac{d \Theta(t)}{d t}=0, \text { at } x=0 \text { and } x=L .
$$

Whence it follows that

$$
\frac{d X(x)}{d x}=0 \text { at } x=0 \text { and } x=L .
$$

Nonzero solutions of Eq. (8) with the conditions (10) we obtain only for the eigenvalues $\lambda=\lambda_{n}$ $(n=0,1,2 \ldots)$ (note that $\lambda_{0}=0$ for $n=0, \lambda_{n}>0$ for others $n$ ). Let denote them $X_{n}(x)$. The functions $X_{n}(x)$ are orthogonal over the interval $(0, L)$ with the weight factor $\rho(x)$, i.e. they satisfy the conditions

$$
\frac{1}{L} \int_{0}^{L} \rho(x) X_{n}(x) X_{m}(x) d x= \begin{cases}\neq 0 & n=m \\ =0 & n \neq m\end{cases}
$$

We can normalize them and obtain an orthonormal system of eigenfunctions

$$
Z_{n}(x)=\frac{X_{n}(x)}{\left\|X_{n}\right\|}, \text { where }\left\|X_{n}\right\|=\left(\frac{1}{L} \int_{0}^{L} \rho(x) X_{n}^{2}(x) d x\right)^{\frac{1}{2}}, \quad n=0,1,2 \ldots
$$

Find the appropriate $\lambda=\lambda_{n}$ of the function $\Theta_{n}(t)$. For $\lambda=\lambda_{0}=0$ this function is linear

$$
\Theta_{0}(t)=a+b t
$$

For $n=1,2, \ldots$ respectively,

$$
\Theta_{n}(t)=e^{-\alpha_{n} t}\left(a \cos \left(\beta_{n} t\right)+b \sin \left(\beta_{n} t\right)\right)
$$

where $\alpha_{n}=\operatorname{Re}(\kappa), \beta_{n}=\operatorname{Im}(\kappa)$, and $\kappa$ is a solution of the quadratic equation $\kappa^{2}+\lambda_{n}^{2} \mu_{u} \kappa+\lambda_{n}^{2}=0$, namely

$$
\alpha_{n}=-\frac{1}{2} \lambda_{n}^{2} \mu_{u}, \quad \beta_{n}=\sqrt{-\left(\frac{\lambda_{n}^{4} \mu_{u}^{2}}{4}-\lambda_{n}^{2}\right)} .
$$

The constants $a$ and $b$ serve to satisfy the initial conditions for the further use of the functions $\Theta_{n}(t)$ to represent the solution of the initial boundary-value problem.

The functions, which depend on $x$, over the interval $[0, L]$ can be represented as series of expansions in terms of $Z_{n}(x)$. A solution of Eq. (4) we also try in the form of expansion

$$
u(x, t)=w_{0}(t) Z_{0}(x)+\sum_{n=1}^{\infty} w_{n}(t) Z_{n}(x)
$$

where $w_{n}(t)$ are time components of the solution, which provide the satisfaction of the initial conditions, and their form for different values of $\lambda_{n}$ is determined by the formulae (12) or (13).

Substitute this representation of $u(x, t)$ into Eq. (4) with the initial conditions (3) (boundary conditions (5) are satisfied as they satisfy the function). Multiply the equation by $\frac{Z_{m}(x)}{L} d x$ and integrate 
over $[0, L]$. Based on the formula (12), for $n=0$ we obtain

$$
\begin{aligned}
\bar{w}_{0}(t)= & \frac{Z_{0}(L)}{L} \int_{0}^{t}(t-\tau) F_{0}(\tau) d \tau-\frac{1}{L} \int_{0}^{t}(t-\tau)\left(\int_{0}^{L} Z_{0}(x) \varpi(x, \tau) d x\right) d \tau \\
& -\frac{Z_{0}\left(x_{*}\right)}{L} \int_{0}^{t}(t-\tau) P_{*}(\tau) d \tau
\end{aligned}
$$

is a solution for zero initial conditions,

$$
\overline{\bar{w}}_{0}(t)=f_{10} t+f_{00}
$$

is a solution of the homogeneous equation with conditions (3). Eventually, $w_{0}(t)=\bar{w}_{0}(t)+\overline{\bar{w}}_{0}(t)$. Here $f_{00}, f_{10}$ are the coefficients of the expansions of the function $f_{0}(x)$ and $f_{1}(x)$, which are the components of the initial condition (3), into series over the orthogonal functions $Z_{n}(x)$

$$
f_{0 n}=\frac{1}{L} \int_{0}^{L} \rho(x) Z_{n}(x) f_{0}(x) d x, \quad f_{1 n}=\frac{1}{L} \int_{0}^{L} \rho(x) Z_{n}(x) f_{1}(x) d x .
$$

For $n=1,2, \ldots$ using (13) we obtain respectively

$$
\begin{aligned}
& \bar{w}_{n}(t)= \frac{Z_{n}(L)}{L \beta_{n}} \int_{0}^{t} e^{\alpha_{n}(t-\tau)} \sin \left(\beta_{n}(t-\tau)\right) F_{0}(\tau) d \tau \\
&-\frac{1}{\beta_{n}} \int_{0}^{t} e^{\alpha_{n}(t-\tau)} \sin \left(\beta_{n}(t-\tau)\right)\left(\frac{1}{L} \int_{0}^{L} \varpi(x, \tau) Z_{n}(x) d x\right) d \tau \\
&-\frac{Z_{n}\left(x_{*}\right)}{L \beta_{n}} \int_{0}^{t} e^{\alpha_{n}(t-\tau)} \sin \left(\beta_{n}(t-\tau)\right) P_{*}(\tau) d \tau \\
& \overline{\bar{w}}_{n}(t)=f_{0 n} e^{\alpha_{n} t} \cos \left(\beta_{n} t\right)+\frac{1}{\beta_{n}}\left(f_{1 n}-\alpha_{n} f_{0 n}\right) e^{\alpha_{n} t} \sin \left(\beta_{n} t\right) .
\end{aligned}
$$

Thus $w_{n}(t)=\bar{w}_{n}(t)+\overline{\bar{w}}_{n}(t)(n=1,2, \ldots)$. Substitute $w_{0}(t)$ and $w_{n}(t)$ into $(15)$, and obtain the formula for calculating the displacements in the longitudinal vibrations of the rod.

\section{Eigenfunctions for the case of piecewise nonuniform rod}

To use the formula (15) for displacements, we need to know the eigenfunctions $X_{n}(x)(n=0,1,2, \ldots)$, satisfying Eq. (8). Let us obtain such eigenfunctions for a rod (Fig. 1), which consists of three uniform parts $\left(0, x_{1}\right),\left(x_{1}, x_{2}\right),\left(x_{2}, L\right)$, assuming conditions of ideal elastically deformed contact between them.

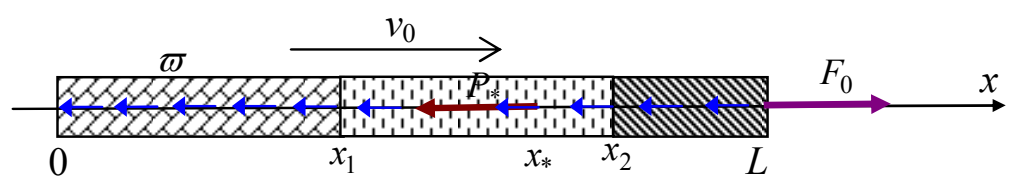

Fig. 1. Piecewise nonuniform rod under the action of external forces. 
We obtain solutions of Eq. (8) with the conditions (10) for the eigenvalues $\lambda=\lambda_{n}(n=0,1,2, \ldots)$ in the form

$$
\begin{aligned}
X_{n}(x)= & {\left[\cos \left(\lambda_{n} \frac{\gamma_{2}}{\gamma_{1}}\left(\xi_{2}-\xi_{1}\right)\right) \cos \left(\lambda_{n} \frac{\gamma_{3}}{\gamma_{1}}\left(1-\xi_{2}\right)\right)\right.} \\
& \left.-\frac{k_{3}}{k_{2}} \frac{\gamma_{3}}{\gamma_{2}} \sin \left(\lambda_{n} \frac{\gamma_{2}}{\gamma_{1}}\left(\xi_{2}-\xi_{1}\right)\right) \sin \left(\lambda_{n} \frac{\gamma_{3}}{\gamma_{1}}\left(1-\xi_{2}\right)\right)\right] \frac{\cos \left(\lambda_{n} x / L\right)}{\cos \left(\lambda_{n} \xi_{1}\right)} \Xi^{-1} \text { for } 0<x<x_{1}, \\
X_{n}(x)= & {\left[\cos \left(\lambda_{n} \frac{\gamma_{2}}{\gamma_{1}}\left(\xi_{2}-\frac{x}{L}\right)\right) \cos \left(\lambda_{n} \frac{\gamma_{3}}{\gamma_{2}}\left(1-\xi_{2}\right)\right)\right.} \\
& \left.-\frac{k_{3}}{k_{2}} \frac{\gamma_{3}}{\gamma_{2}} \sin \left(\lambda_{n} \frac{\gamma_{2}}{\gamma_{1}}\left(\xi_{2}-\frac{x}{L}\right)\right) \sin \left(\lambda_{n} \frac{\gamma_{3}}{\gamma_{1}}\left(1-\xi_{2}\right)\right)\right] \Xi^{-1} \text { for } x_{1}<x<x_{2}, \\
X_{n}(x)= & \cos \left(\lambda_{n} \frac{\gamma_{3}}{\gamma_{1}}\left(1-\frac{x}{L}\right)\right) \Xi^{-1} \text { for } x_{2}<x<L
\end{aligned}
$$

where

$$
\Xi=\cos \left(\lambda_{n} \frac{\gamma_{2}}{\gamma_{1}} \xi_{2}\right) \cos \left(\lambda_{n} \frac{\gamma_{3}}{\gamma_{1}}\left(1-\xi_{2}\right)\right)-\frac{k_{3}}{k_{2}} \frac{\gamma_{3}}{\gamma_{2}} \sin \left(\lambda_{n} \frac{\gamma_{2}}{\gamma_{1}} \xi_{2}\right) \sin \left(\lambda_{n} \frac{\gamma_{3}}{\gamma_{1}}\left(1-\xi_{2}\right)\right)
$$

$\xi_{1}=\frac{x_{1}}{L}, \xi_{2}=\frac{x_{2}}{L}, \gamma_{i}=\sqrt{\frac{\rho_{i}}{k_{i}}}, \rho_{i}$ is a linear density, $k_{i}$ is the reduced modulus of elasticity of the $i$-th part of the $\operatorname{rod} i=1,2,3$. The eigenvalues $\lambda_{n}$ we obtain by solving the characteristic equation

$$
\begin{aligned}
& \sin \left(\lambda \gamma_{1} x_{1}\right)\left[\cos \left(\lambda \gamma_{2}\left(x_{2}-x_{1}\right)\right) \cos \left(\lambda \gamma_{3}\left(L-x_{2}\right)\right)-\frac{k_{3}}{k_{2}} \frac{\gamma_{3}}{\gamma_{2}} \sin \left(\lambda \gamma_{2}\left(x_{2}-x_{1}\right)\right) \sin \left(\lambda \gamma_{3}\left(L-x_{2}\right)\right)\right] \\
&+\cos \left(\lambda \gamma_{1} x_{1}\right)\left[\frac{k_{2}}{k_{1}} \frac{\gamma_{2}}{\gamma_{1}} \sin \left(\lambda \gamma_{2}\left(x_{2}-x_{1}\right)\right) \cos \left(\lambda \gamma_{3}\left(L-x_{2}\right)\right)-\frac{k_{3}}{k_{1}} \frac{\gamma_{3}}{\gamma_{1}} \cos \left(\lambda \gamma_{2}\left(x_{2}-x_{1}\right)\right) \sin \left(\lambda \gamma_{3}\left(L-x_{2}\right)\right)\right] \\
&=0 .
\end{aligned}
$$

It is obvious that $\lambda_{0}=0, X_{0}(x)=1$ and according to (11) $Z_{0}(x)=\sqrt{\frac{L}{M}} \equiv$ const. Here $M$ is the rod weight, $L$ is its length. Then the displacement $w_{0}(t) Z_{0}(x)$ in the formula (15) is the displacement of the mass center of the rod under the influence of external forces. This component of the total displacement (15) does not affect the change in time of the internal longitudinal force.

To calculate the displacement $u(x, t)$ and the force $\Phi(x, t)$ by the formula $(6)$, let us determine the orthonormal function $Z_{n}(x) n=1,2, \ldots$ by the formulae (11).

\section{Data formation of the problem}

To carry out the numerical calculations, we need to write down the form of distributed forces of resistance, initial conditions, and to determine the coefficients of the problem. Let us obtain the initial data by example of a moving train consisting of locomotive and $n$ railway freight wagons, moving at a coqnstant speed $v_{0}$.

The train may include unequally loaded freight wagons of various types and so the value of main resistivity for them will be different. The masses of the locomotive $m_{0}$ and loaded freight wagons $m_{i}$ $(i=\overline{1 ; n})$ when the train starts moving are given. The total length of the train $L=l_{0}+\sum_{i=1}^{n} l_{i}$ is represented as a sum of lengths of the locomotive $l_{0}$ and freight wagons $l_{i}$. We assume that the origin is at the tail end of the train. Then the density function $\rho(x)$ on the intervals that occupies each unit of the rolling stock is obtained in the form $\rho(x)=\rho_{i} \equiv \frac{m_{i}}{l_{i}}$, for $x \in\left(x_{n-i}, x_{n-i+1}\right), i=\overline{0 ; n} x_{0}=0$, $x_{n+1}=L$. The total mass of the train-rod is calculated according to the formula $M=\int_{0}^{L} \rho(x) d x$ or $M=\sum_{i=0}^{n} \rho_{i} l_{i}$ 
Writing the function $\varpi(x, t)$ of distributed resistance to motion, we ignore its changes in time because just after applying the additional force $P_{*}(t)$, the general speed of the train $v_{0}$ does not have time to change significantly. The dependence $\varpi(x)$ on the main resistivity to motion and other types of resistance for different speeds $v_{0}$ and for different types of the moving set of the train can be written as polynomials with coefficients values found experimentally. Formulae of resistance to motion for different types of freight wagons and locomotives in the quadratic approximation can be found in a number of works and in the Rules of traction calculations [16-18].

Distributed along the length of the rod, the power resistance to motion is determined by the formula

$$
\varpi(x)=\frac{\vartheta_{0 i}}{l_{i}} m_{i} g, \quad x \in\left(x_{n-i}, x_{n-i+1}\right) \quad(i=\overline{0 ; n}),
$$

where $\vartheta_{0 i}$ is the general main resistivity of the $i$-th unit of the train including the locomotive $(i=0)$.

Due to this definition the function $\varpi(x)$ is piecewise continuous on the interval $(0, L)$ and is independent on $t$ when the train is moving at the constant speed $v(t)=v_{0}$.

If on the straight section under the force $F(t)=F_{0} \equiv$ const the train is moving at a constant speed, the traction force and the resistance force are balanced with each other, i.e. $F_{0}=\int_{0}^{L} \varpi(\xi) d \xi$. Moreover, the elastically deformed state of the rod under the action of external forces corresponds to the stationary state. If at the initial time of observation the dynamic components of displacement are absent, the train-rod will be strained. Let denote $u_{0}(x)$ the rod particle displacement. Then $\varepsilon(x)=\frac{d u_{0}(x)}{d x}$ is its longitudinal deformation, and $k(x) \frac{d u_{0}(x)}{d x}=F(x)$ is the internal force reduced to the axis. Since this force is balanced with distributed forces of resistance, here we obtain the equation

$$
k(x) \frac{d u_{0}(x)}{d x}=\int_{0}^{x} \varpi(\xi) d \xi
$$

and the formula to calculate displacements

$$
u_{0}(x)=\int_{0}^{x}\left(\frac{1}{k(x)} \int_{0}^{x} \varpi(\xi) d \xi\right) d x .
$$

Taking this state to be an initial state, we write down the functions $f_{0}(x)$ and $f_{1}(x)$ for the initial conditions in the form

$$
f_{0}(x)=u_{0}(x), \quad f_{1}(x)=v_{0} .
$$

The numerical values of a number of parameters needed for input data are obtained from the reference books and documents on transportations [16]. The evaluation of the coefficient of inelastic resistance $\mu_{u}$ can be performed according to the dynamic behaviour of the rod, the propagation, and the form of the elastic wave.

\section{The calculation and analysis of dynamic behavior of moving rod}

Let us carry out control calculations for the rod (Fig. 1), which consists of three connected uniform parts. The traction force $F_{0}$ and the distributed resistance forces $\varpi(x)$ are balanced and the strained by them rod at the initial time is moving uniformly with the speed $v_{0}$.

If at the time $t=0$ when $x=x_{*}$ the additional force of resistance $P_{*}$ suddenly emerges, which acts in the opposite direction to the traction $F_{0}$, in the core the wave processes arrive due to a sudden application of the force, the nature of which depends on its magnitude as well as on the parameters and characteristics of the rod. We assume that the distributed forces of resistance $\varpi(x)$ immediately 
after application $P_{*}$ do not change in time because they depend on the speed and we assume that the speed of the rod as a whole in a short period of time has not changed significantly.

Parameters and characteristics of the rod are the following: $x_{1}=400 \mathrm{~m}, x_{2}=800 \mathrm{~m}, L=1000 \mathrm{~m}$; the linear density of the parts $\rho_{1}=6000 \mathrm{~kg} / \mathrm{m}, \rho_{2}=4000 \mathrm{~kg} / \mathrm{m}, \rho_{3}=7000 \mathrm{~kg} / \mathrm{m}$; the reduced modulus of elasticity $k_{1}=4 \cdot 10^{6} \mathrm{~N}, k_{2}=3 \cdot 10^{6} \mathrm{~N}, k_{3}=9 \cdot 10^{6} \mathrm{~N}$; the traction force $F_{0}=1.8 \cdot 10^{5} \mathrm{~N}$. The distributed force of resistance on the $\operatorname{rod}$ parts $\varpi_{1}=200 \mathrm{~N} / \mathrm{m}, \varpi_{2}=100 \mathrm{~N} / \mathrm{m}, \varpi_{1}=300 \mathrm{~N} / \mathrm{m}$; $v_{0}=20 \mathrm{~m} / \mathrm{s}$; the additional force of resistance $P_{*}=1.8 \cdot 10^{5} \mathrm{~N}$ applied to the section $x_{*}=700 \mathrm{~m}$.

The initial displacements due to the strain by the given forces $F_{0}$ and $\varpi(x)$ are obtained by the formula (23). Write them as follows

$$
u(x, 0)= \begin{cases}k_{0}^{-1} \omega_{0} \frac{x^{2}}{2}, & 0<x<x_{1}, \\ k_{0}^{-1} \omega_{0} \frac{x_{1}^{2}}{2}+k_{1}^{-1}\left(\omega_{0} x_{1}\left(x-x_{1}\right)+\omega_{1} \frac{\left(x-x_{1}\right)^{2}}{2}\right), & x_{1}<x<x_{2}, \\ k_{0}^{-1} \omega_{0} \frac{x_{1}^{2}}{2}+k_{1}^{-1}\left(\omega_{0} x_{1}\left(x_{2}-x_{1}\right)+\omega_{1} \frac{\left(x_{2}-x_{1}\right)^{2}}{2}\right) & \\ +k_{2}^{-1}\left(\omega_{0} x_{1}\left(x-x_{2}\right)+\omega_{1}\left(x_{2}-x_{1}\right)\left(x-x_{2}\right)+\omega_{2} \frac{\left(x-x_{2}\right)^{2}}{2}\right), & x_{2}<x<L\end{cases}
$$

and use then in solving problems for the initial conditions.

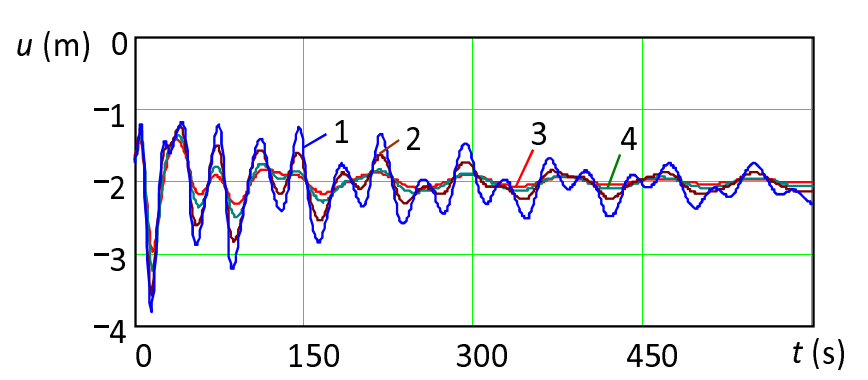

Fig. 2. Longitudinal vibrations in the middle part of the $\operatorname{rod} x=500 \mathrm{~m}$. Curves $1-4$ correspond to the different values of the coefficient of inelastic resistance

$$
\mu_{u}=0.05 ; 0.25 ; 0.5 ; 1 \mathrm{~s} \text {. }
$$

Calculate the deformation displacements according to the formula (15) for some values of $\mu_{u}$, excluding the motion of the rod as a whole.

In Fig. 2 there are shown the displacements in the middle part of the rod $(x=500) \mu_{u}=$ $0.05 ; 0.25 ; 0.5 ; 1 \mathrm{~s}$. The displacements are sensitive to changes of the coefficient of inelastic resistance at $\mu_{u}<0.5$. This gives grounds to obtain values of $\mu_{u}$ if to obtain data on the change of the parameters of vibration. For the greater values of $\mu_{u}$ the sensitivity decreases. The same happens with the increasing time of the observation, because eventually vibrations are damped.

With increasing viscosity of the rod, the vibrations are damped significantly faster. Then the accuracy requirements for the input $\mu_{u}$ are lower.

Let us give for some values of $\mu_{u}$ the graphs of changes of the function of the force $\Phi(x, t)(6)$ along the length $x$ of the rod at $t=5 \mathrm{~s}$ (Fig. $3 a$ ), and at $t=25 \mathrm{~s} \mathrm{(Fig.} \mathrm{3b).} \mathrm{Parameters} \mathrm{and} \mathrm{characteristics} \mathrm{of}$ the rod are those that have been given above. Curves 1-5 in these figures correspond to the following values $\mu_{u}=0 ; 0.05 ; 0.1 ; 0.25 ; 0.5$. As the force $P_{*}$ is applied suddenly at the initial time $t=0$ and then remains constant, at the point of force application $x_{*}$ the function $\mathrm{f} \Phi(x, t)$ for $t>0$ has the jump of the magnitude of $P_{*}$. From this point, the disturbance extends in both directions. In the case of an elastic $\operatorname{rod} \mu_{u}=0$, the wave has a spasmodic form and is not damped, but partially passes through the inner surface of the rod material changes, and partly is reflected from them, and also is reflected from the ends of the rod. The superposition of the reflected waves and waves that passed the inner borders forms a complex picture of changes of the elastically deformed state of the rod. If the rod is viscoelastic, the wave front is smoothed (curves 2-5), and the more it is smoothed, the more the value of $\mu_{u}$ is. During passing and being reflected from the inner surface $(x=800)$ the viscosity causes the distortion of the waves. This is observed in Fig. $3 a)(t=5 \mathrm{~s})$. Note that for the rod under consideration, for $\mu_{u}>0.5$ the curves in the graphs differ slightly. That confirms the decrease of sensitivity to changes of this parameter. 

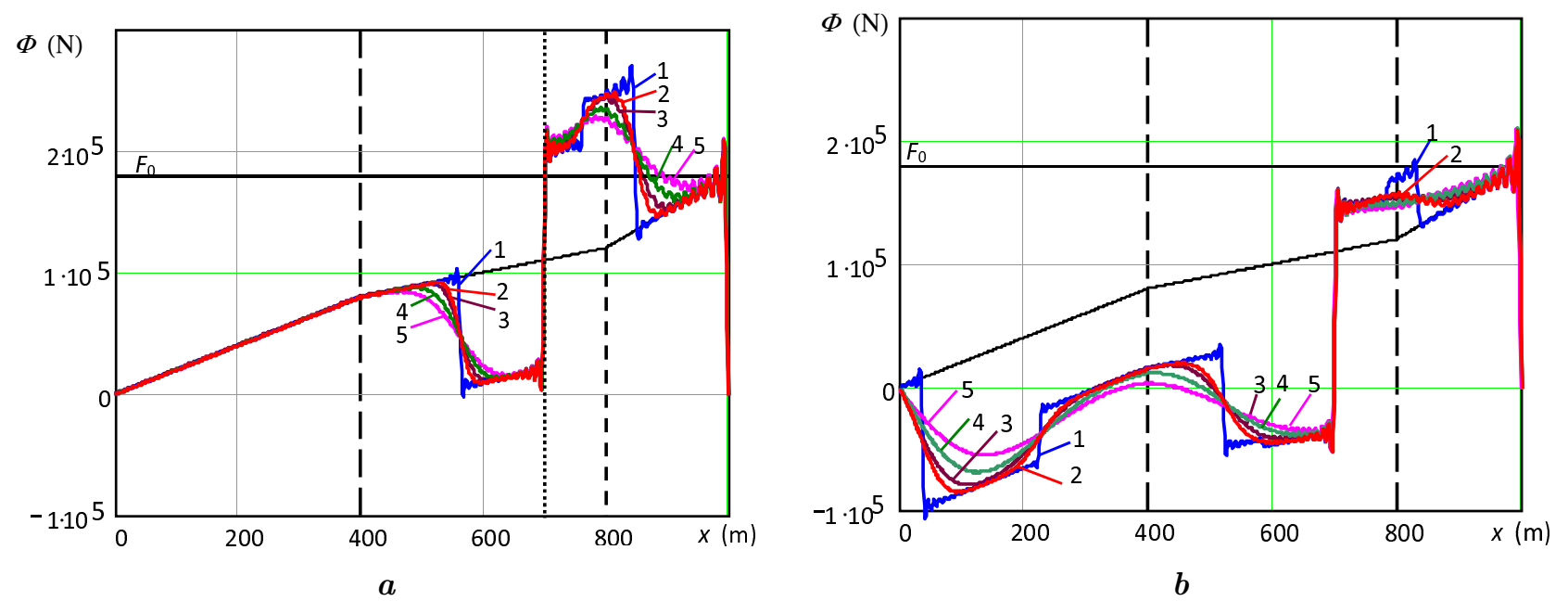

Fig. 3. Change of the inner longitudinal force $\Phi(x, t)(\mathrm{N})$ with respect to rod length at the moment $t=5 \mathrm{~s}$ (Fig. $3 a$ ) and at $t=25 \mathrm{~s}$ (Fig. $3 b$ ) for different values of $\mu_{n}$. Curves $1-5$ correspond to the values $\mu_{n}=$ $0 ; 0.05 ; 0.1 ; 0.25 ; 0.5$.

Show the change of the stress state of the rod at its various points for several moments of time. In Fig. $4 \mathrm{a}, \mathrm{b}$, the graphics are presented for changes along the rod length of the inner longitudinal force calculated at $\mu_{u}=0.5$ for some moments of time immediately after applying the force $P_{*}$.
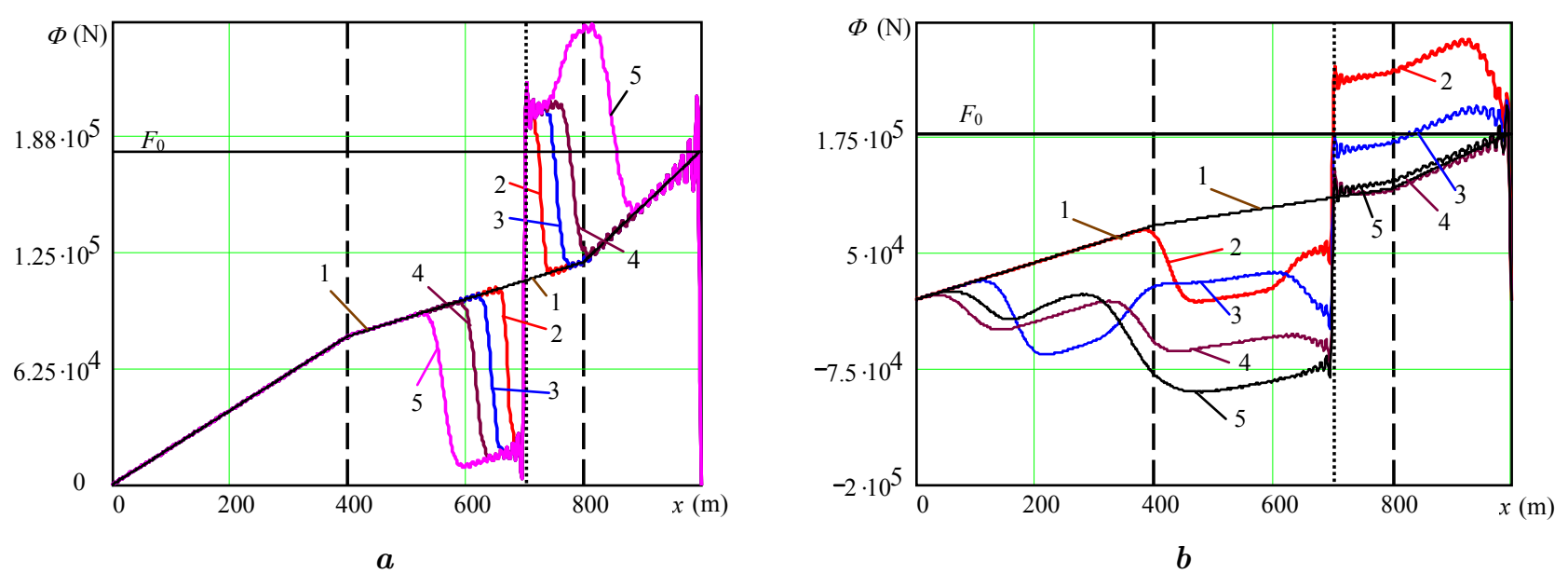

Fig. 4. Function of inner longitudinal force $\Phi(x, t)$ : a) curves $1-5$ correspond to moments $t=0 ; 1 ; 2 ; 3 ; 5 \mathrm{~s}$; $b$ ) curves $1-5$ correspond to moments $t=0 ; 10 ; 20 ; 30 ; 40 \mathrm{~s}$.

The elastic wave propagating in both directions from the point of application of $P_{*}$, and the caused by it force lay over the initial distribution of forces emerged under the action of traction force $F_{0}$ and the resistance force to motion $\varpi(x)$ (curve 1). As a result, the tensile force in the domain $x<x_{*}$ is reduced, while for $x>x_{*}$ it increases and may exceed the value of $F_{0}$. Over time, when $x<x_{*}$ the deformation forces are compressive and inner forces have the negative values (Fig. 4b).

Especially significant deformations and the caused by them stresses occur at the time just after the sudden application of the force $P_{*}$. With the increase of time, due to scattering of vibrational energy, the rod should transit slowly into the steady state. Note that for objects that have a different resistance to motion at different speeds, we must also take into account the dependence of the force $\varpi(x, t)$ on time $t$. The performed calculations do not provide for such a dependence, but the mathematical model allows us to consider such problems. 


\section{Conclusions}

The problem describing the dynamic behavior of longitudinally nonuniform viscoelastic rod that moves under the action of traction force and in the presence of the distributed forces of resistance is formulated. The obtained solution of the considered problem allows writing down the mathematical formulae for dynamic displacements, deformations and longitudinal forces for a sudden application of a local force directed against the motion. The proposed approach gave us the opportunity to analyse the dynamic process development in the rod depending on its parameters and mechanical characteristics. The values of the coefficient of material inelastic resistance are of a particular interest. The performed calculations showed that in the first seconds after a sudden application of a force directed against the motion, the dynamic effects lead to a local increase in the internal tensions. Taking into account the viscosity does not lead to their values substantial decrease. It leads to smoothing the wave front and to its distortion as a result of reflections from the inner surfaces when considering a piecewise nonuniform rod. An intensive force localized within the rod causes the strain increase of its parts where the traction force is applied, and a significant increase of the inner forces within it. With this, in the running over part of the rod, the compressive deformations and negative forces that can be evaluated in each particular case.

[1] Abramson H. N., Plass H. J., Ripperger E. A. Stress Wave Propagation in Rods and Beams. Adv. in Appl. Mech. 5, 111-194 (1958).

[2] Timoshenko S. P., Goodier J. N. Theory of elasticity. McGraw-Hill, N.Y. (1970).

[3] Ke Yang. A unified solution for longitudinal wave propagation in an elastic rod. J. Sound and Vibr. 314 $(\mathbf{1}, \mathbf{2}), 307-329,(2008)$.

[4] Fu Y. B., Scott N. H. Propagation of simple waves and shock waves in a rod of slowly varying cross-sectional area. Int. J. Engn. Sci. 32 (1), 35-44 (1994).

[5] Chunbiao Gan, Yimin Wei, Shixi Yang. Longitudinal wave propagation in a rod with variable cross-section. J. Sound and Vibr. 333, 434-445 (2014).

[6] Guo S., Zhang Z., Yang S. Longitudinal waves in one-dimensional non-uniform waveguides. Theor. Appl. Mech. Lett. 2, 021007 (2011).

[7] Li Q. S. Exact solutions for free longitudinal vibrations of non-uniform rods. J. Sound and Vibr. 234, 1-19 (2000).

[8] Kumar B. M., Sujith R. I. Exact solutions for the longitudinal vibration of non-uniform rods. J. Sound and Vibr. 207, 721-729 (1997).

[9] Li Q.S. Exact solutions for free longitudinal vibration of stepped non-uniform rods. Appl. Acoustics. 60, 13-28 (2000).

[10] Gera B. Determining of the optimal transient conditions of longitudinal loading for moving one-dimensional elastic system. Physical Modeling and Information Technology. 13, 21-30 (2011), (in Ukrainian).

[11] Schuler K. W., Nunziato J. W., Walsh E. K. Recent results in nonlinear viscoelastic wave propagation. Int. J. Solids and Struct. 9, 10, 1237-1281 (1973).

[12] Campos L. M. B. C., Santos A. J. P. On the propagation and damping of longitudinal oscillations in tapered visco-elastic bars. J. Sound and Vibr. 126 (1), 109-125 (1988).

[13] Lazaryan V.A., Blokhin E. P., BelikL.V. Longitudinal vibrations of nonlinear systems in the onedimensional perturbations propagating along their length. J Appl. Mech. 9 (6), 89-94 (1973), (in Russian).

[14] Lazaryan V. A., Manashkin L. A., Ryzhov A. V. The longitudinal vibrations of elastic rods at propagating perturbations. J. Appl. Mech. 10 (5), 132-137 (1975), (in Russian).

[15] Blokhin E. P., Manashkin L. A. Train dynamics (nonstationar longitudinal vibrations). Moscow, Transport (1982) (in Russian).

[16] Grebenyuk P. T., Dolganov A. N., Skvortsova A. I. Traction calculations. Moscow, Transport (1987), (in Russian). 
[17] Sitarz M., Nowak A., Manka A. Modelling of the dynamics of the railway vehicle by use of the networks graphs. Visnik of the East Ukrainian National University, Transport. 1 (6), 57-61 (2002).

[18] Sitarz M., Nowak A., Verbicki W. Analysis of the Brake-Wheelset Raiway Dynamics during the Motion. Mechanika. 2 (46), 52 (2004).

\title{
Поздовжні коливання в'язко-пружного поздовжньо неоднорідного стрижня під дією розподіленого по його довжині силового навантаження
}

\author{
Гера Б. ${ }^{1}$, Сітаж М. ${ }^{2}$, Болжеларський Я. ${ }^{1}$
}

${ }^{1}$ Дніпропетровсъкий національний університет залізничного транспорту імені академіка В. Лазаряна вул. Іванни Блажкевич, 12а, 79052, Львів, Украӥна

${ }^{2}$ Вища школа бізнесу

1с Цеплака, 41-300, Дамброва Гурніча, Польща

\begin{abstract}
Динамічну поведінку рухомого видовженого об'єкта змодельовано з використанням співвідношень для в'язко-пружного стрижня, котрий рухається зі сталою швидкістю під дією сили тяги та розподілених по його довжині сил зовнішнього опору. Досліджено зміну переміщень і внутрішніх сил після раптового прикладання в його перерізі локальної сили у поздовжньому напрямку. Записано співвідношення початковокрайової задачі, що описує динамічну поведінку стрижня, та отримано її розв'язок у вигляді розвинення в ряд за власними функціями. Для в'язко-пружного стрижня, що складається з трьох з'єднаних однорідних стрижнів, проведено аналіз хвильових процесів, викликаних раптовим прикладанням в області стрижня зосередженої сили, що чинить опір рухові. Це впливає на рух стрижня як цілого, а також викликає хвильові процеси, проходження і відбивання хвиль на внутрішніх поверхнях з'єднань. Приведено порівняння поведінки пружного кусково-неоднорідного стрижня та в'язко-пружного стрижня з різними механічними характеристиками, де хвилі під час поширення загасають і згладжуються.
\end{abstract}

2000 MSC: $74 \mathrm{H} 10$

Удк: 539.3 